\title{
Characteristics of a Half-Wave Rectified Brushless
}

\section{Synchronous Generator}

\author{
Yuki Hirakawa, Tsuyoshi Higuchi, Yuichi Yokoi and Takashi Abe \\ Graduate School of Engineering \\ Nagasaki University \\ 1-14 Bunkyo, Nagasaki 852-8521, Japan \\ thiguchi@nagasaki-u.ac.jp
}

\begin{abstract}
The paper proposes the half-wave rectified brushless synchronous generator and analyzes the basic characteristics using the finite element method. It is based on the half-wave rectified excitation theory and doesn't need brush and slip ring system or permanent magnets for field excitation.
\end{abstract}

Keywords- Synchronous generator, half-wave rectified excitation theory, wind power generation, finite element analysis

\section{INTRODUCTION}

Previously we developed the half-wave rectified brushless synchronous motor [1] [2], as an AC servo motor. In this paper we propose a novel synchronous generator for wind power generation using the half-wave rectified excitation theory. The structure is the same as conventional salient pole type synchronous generator, but whose rotor windings are short circuited with a diode. The field current in the rotor field windings is induced from the stator excitation current and produces a field magnetic flux. The field flux is controllable by varying the amplitude of the excitation current. The controllability makes it possible to easily perform the field weakening operation at high speed region of the vertical axis wind turbine type generation system. It doesn't need any permanent magnet for field excitation and so cut-in wind speed is smaller than permanent magnet type generator. The basic characteristics are calculated using the finite element method (FEM) analysis.

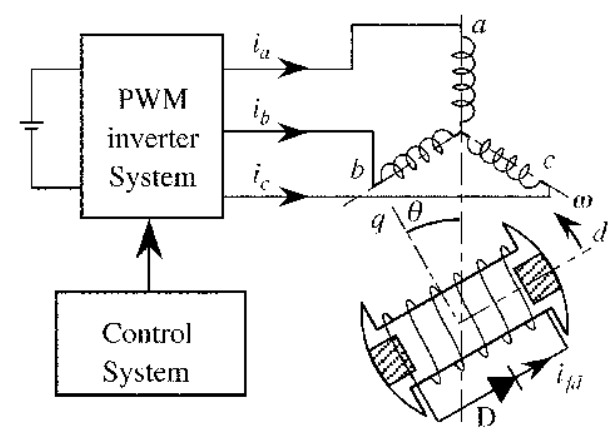

Fig. 1 Motor system configuration.

\section{HALF-WAVE RECTIFIED BRUSHLESS SYNCHRONOUS MOTOR}

Figure 1 shows the system configuration of the half-wave rectified brushless synchronous motor[1] [2]. The machine structure is the same as conventional salient pole type synchronous motor, but whose rotor winding is short circuited through a diode. On the rotor, permanent magnets are attached for additional torque generation [3], but they are not necessary for torque generation fundamentally. The control system produces 3-phase current commands necessary for the motor drive. The PWM inverter is implemented to generate 3-phase currents according to the commands.

Fig. 2 shows the dq-axis model of the motor. The dq-axis voltage equations are, 


$$
\begin{aligned}
& e_{d}=(\mathrm{d} / \mathrm{dt}) \lambda_{d}-\omega \lambda_{q}+r_{a} \\
& e_{q}=(\mathrm{d} / \mathrm{dt}) \lambda_{q}+\omega \lambda_{d}+r_{a} i_{q} \\
& e_{f d}=(\mathrm{d} / \mathrm{dt}) \lambda_{f d}+r_{f d} i_{f d}
\end{aligned}
$$

where, $e_{d}$ is the d-axis voltage, $e_{q}$ is the q-axis voltage, $e_{f d}$ is the excitation voltage, $i_{d}$ is the d-axis current, $i_{q}$ is the q-axis current, $i_{f d}$ is the excitation current, $r_{a}$ is the stator winding resistance, $r_{f d}$ is the field winding resistance, $\lambda_{d}$ is the d-axis flux linkage with the stator winding, $\lambda_{q}$ is the q-axis flux linkage with the stator winding, $\lambda_{f d}$ is the flux linkage with the field winding.

The flux linkages are expressed in terms of self-inductance $L$ and mutual- inductance $M$, as follow;

$$
\begin{aligned}
& \lambda_{d}=L_{d} i_{d}+M_{f d} i_{f d}+\left(M_{f d} / L_{f d}\right) \lambda_{P M} \\
& \lambda_{q}=L_{q} i_{q} \\
& \lambda_{f d}=M_{f d} i_{d}+L_{f d} i_{f d}+\lambda_{P M}
\end{aligned}
$$

Fig. 3 illustrates the principle of the brushless excitation and torque generation. The following 3-phase currents are supplied to the 3-phase stator windings in Fig. 1;

$$
\begin{aligned}
& i_{a}=A_{f}(t) \sin \theta+\sqrt{2} I_{t} \cos \theta \\
& i_{b}=A_{f}(t) \sin (\theta-2 \pi / 3)+\sqrt{2} I_{t} \cos (\theta-2 \pi / 3) \\
& i_{c}=A_{f}(t) \sin (\theta-4 \pi / 3)+\sqrt{2} I_{t} \cos (\theta-4 \pi / 3)
\end{aligned}
$$

The first term on the right-hand side of (3) is excitation current, which varies with sin of the rotor position $\theta$ and whose amplitude is a modulation function $A_{f}(t) . A_{f}(t)$ is a triangular wave function with the effective value of $I_{f}$ and whose frequency is bias frequency $\omega_{b}$. The second term of the equation is torque current component.

The dq-axis currents become;

$$
\begin{aligned}
i_{d} & =\sqrt{3 / 2} A_{f}(t) \\
i_{q} & =\sqrt{3} I_{t}
\end{aligned}
$$

We can obtain such rotating field as if the single phase current $i_{d}$ and the single phase DC current $i_{q}$ are supplied to the dq-axis windings which rotate synchronously with the rotor. As long as the flux linkage $\lambda_{f d}$ is increasing, electro motive force in the field winding biases the diode negatively and the diode turns off. When the flux linkage begins to decrease, the diode turns on and the field current starts to flow and compensates the flux decrease. If the time constant is large enough, the flux is almost constant and is kept its maximum value by the diode.

The torque is obtained from the following equation;

$$
\tau=\lambda_{d} i_{q}-\lambda_{q} i_{d}
$$

Though a pulsating torque exists in this motor as shown in Fig. 3, it is not serious problem for practical usage, by choosing the bias angular frequency much greater than the mechanical resonance frequency.

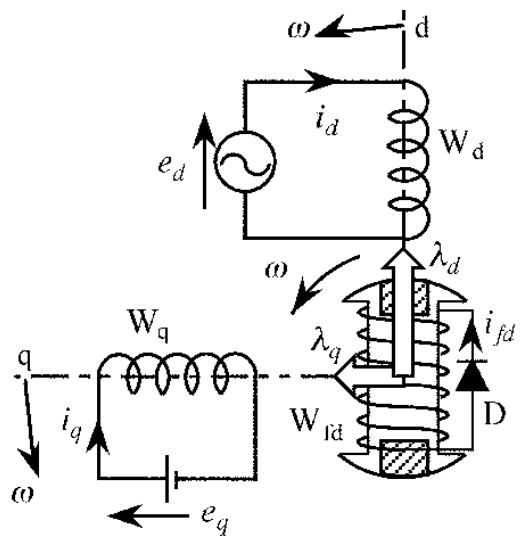

Fig. 2 Motor principle on dq-axis.

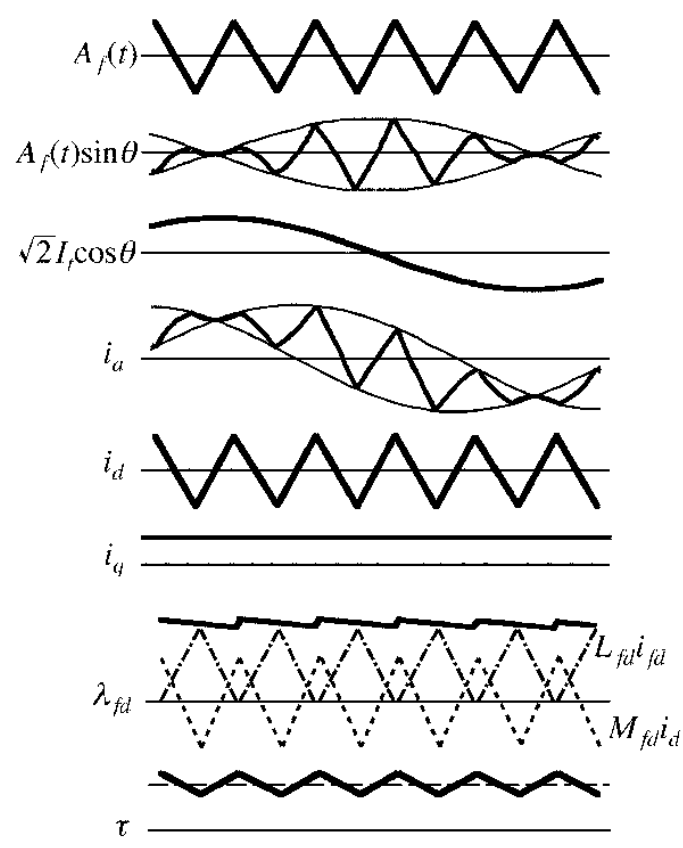

Fig. 3 Waveform of current, flux and torque.

\section{PRINCIPLE OF HALF-WAVE RECTIFIED BRUSHLESS SYNCHRONOUS GENERATOR}

Fig. 4 shows $2 \mathrm{~kW}$ analytical generator model and its dimensions. We call it model 1. It has an excitation winding and the armature winding within the same stator slot. They are short pitch distributed winding and their short pitch factor is $7 / 9$. The generator has a simple and robust brushless structure and is maintenance free, in which the field winding is shortcircuited with a diode. It has no permanent magnets.

Equation (6) is the excitation current, which varies with sine of the mover position and whose amplitude is modulated by a function $A_{f}(t)$. Where, $A_{f}(t)$ is a triangular wave.

$$
\left\{\begin{array}{l}
i_{a}=A_{f}(t) \sin \theta \\
i_{b}=A_{f}(t) \sin (\theta-2 \pi / 3) \\
i_{c}=A_{f}(t) \sin (\theta-4 \pi / 3)
\end{array}\right.
$$


Then, the d-axis current becomes equation (7).

$$
i_{d}=\sqrt{3 / 2} A_{f}(t)
$$

If three-phase alternating current is given by equation (6) in the excitation winding, on the d-axis, magneto motive force that alternates bias frequency is generated by the current $i_{d}$ as shown in Fig. 5. The magneto motive force alternating with the bias frequency $\omega_{b}$ is generated on the d-axis of the rotor. For the increase of the flux linkage with the field winding, the diode turns off. When the flux linkage decreases, the diode turns on. In other words, the field current $i_{f d}$ flows through the field winding to keep the flux linkage constant. The field current is easily controllable by varying the effective value of $A_{f}(t)$.

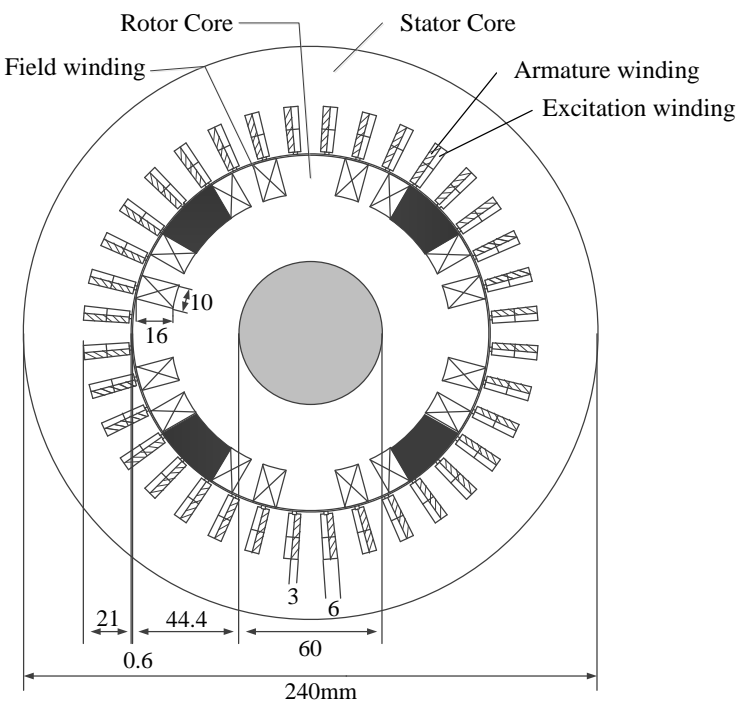

Fig. 4 Analytical model (model 1).

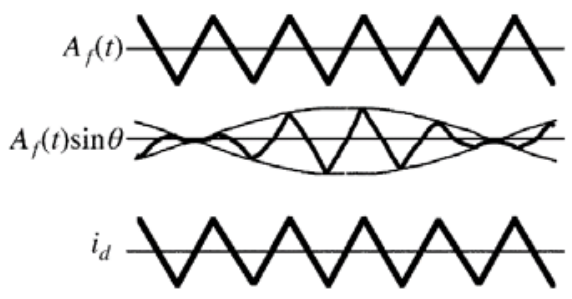

Fig. 5 Wave form of d-axis current.

\section{ANALYTICAL RESULTS}

\section{A. Induced Voltage}

Two-dimensional FEM analysis is carried out with varying the load resistance. Two functions are considered for the modulation function $A_{f}(t)$; triangular function with a peak value of $12.9 \mathrm{~A}$ and sine wave function with the same RMS current value. The no-load induced voltage at the armature winding and flux linkage under triangular function modulation are shown in Fig. 6. Fig. 7 shows the characteristics for 10deg skew model as shown in Fig. 8. Those of sine wave function modulation are shown in Fig. 9 and Fig. 10.

There are many pulse components in the induced voltage under triangular function modulation. The pulse components are produced at turn on and off of the diode. Under sine wave function modulation, the pulse components are decreased.

\section{B. Output Power and Efficiency}

Load characteristics are simulated using the circuit of Fig. 11. $\quad L$ and $R$ loads are connected to the armature winding. Their values can be varied.

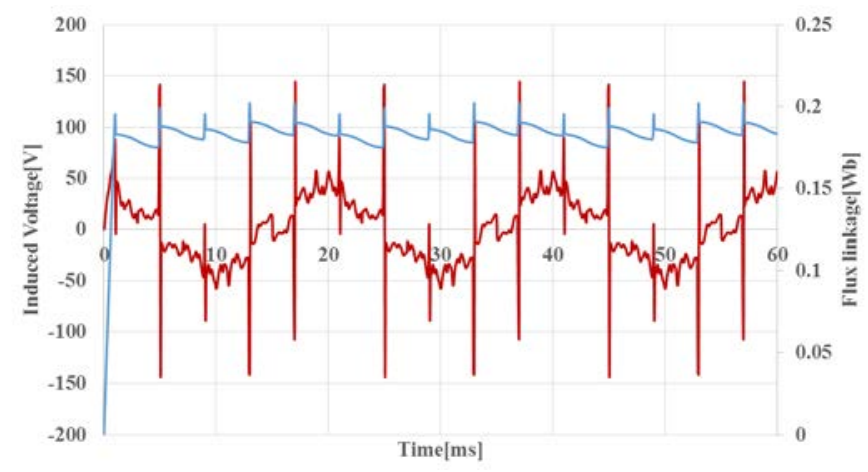

Fig. 6 Induced voltage and flux linkage (triangular wave).

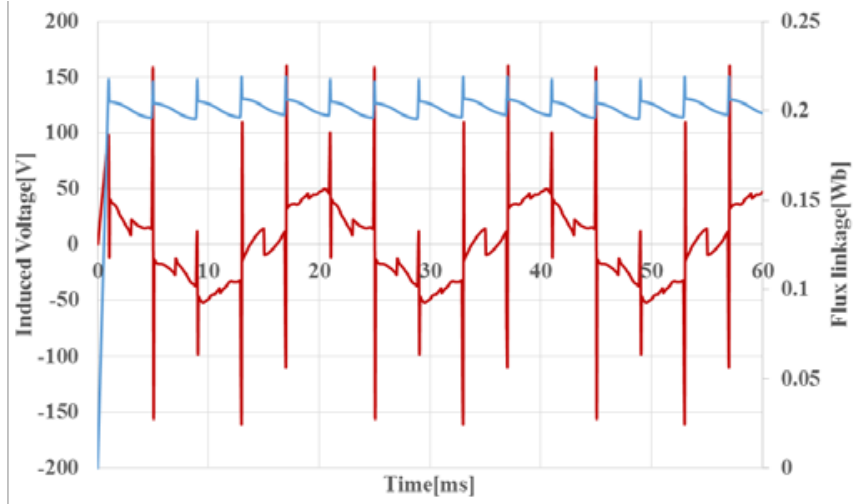

Fig. 7 Induced voltage and flux linkage (triangular wave). (Skew) 


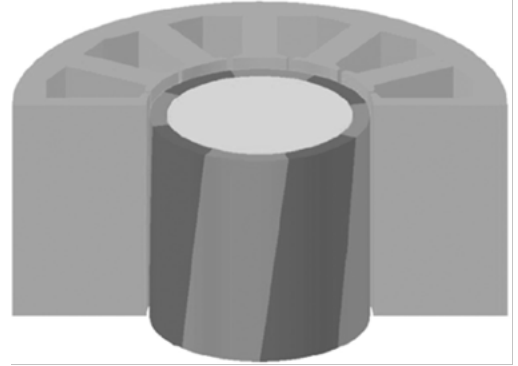

Fig. 8 Skew model

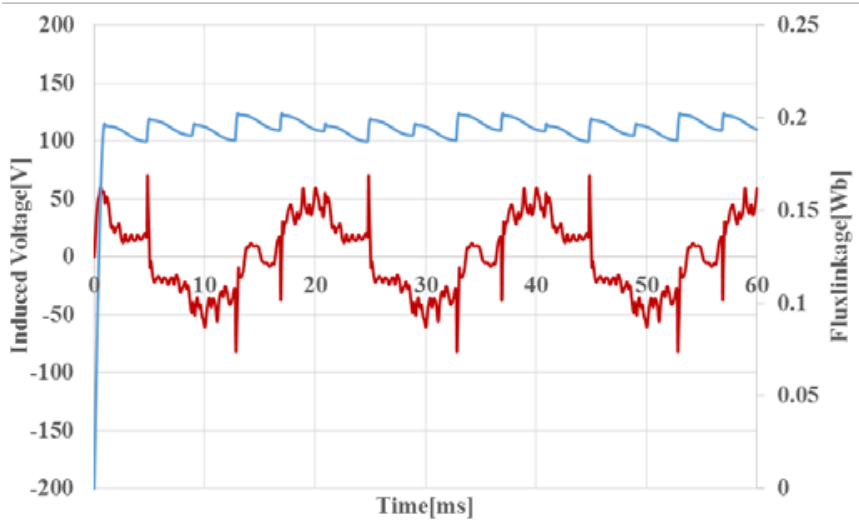

Fig. 9 Induced voltage and flux linkage (sin wave).

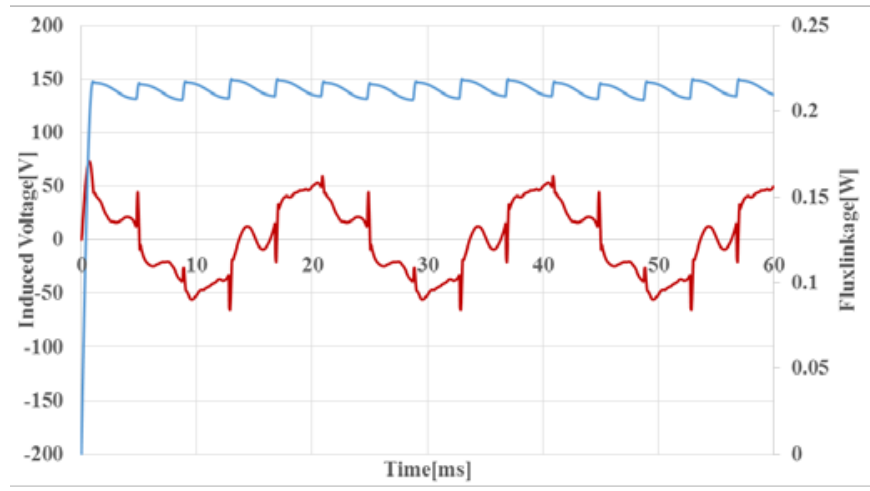

Fig. 10 Induced voltage and flux linkage (sin wave) (Skew)

Fig. 12 shows the output power characteristics for varying $R$. $L$ is constant, $0.01 \mathrm{mH}$. The following three models are simulated; (1) the number of turns of the excitation winding is 16 and number of turns of the armature winding is 12, (2) 14 and 14, (3) 12 and 12, respectively. The model (1) produces the largest output and is $2 \mathrm{~kW}$.

The efficiency is calculated using the following formula.

$$
\eta=\frac{P_{o}}{P_{o}+P_{c}+P_{i}} \times 100
$$

$P_{\mathrm{o}}$ : Output power $P_{\mathrm{i}}$ : Iron loss $P_{\mathrm{c}}$ : Copper loss of the excitation and armature windings
Fig. 13 shows the maximum output power and efficiency for varying the number of turns of the armature winding at 12 turns of excitation winding. Fig. 14 shows the same simulation at 16 turn's excitation winding. Table 1 shows the maximum values of output power and efficiency. The space factor is 49.3 and $61.6 \%$, respectively. It is shown that the output power is 2 $\mathrm{kW}$ and the efficiency is $85 \%$ at the combination of 16 turns excitation winding and 13 turns armature winding.

\section{Performance Improvement}

Fig. 15 shows a new model (model 2). The rotor field winding is changed to concentrated windings. The short pitch factor $\beta$ of the stator fractional pitch winding is $7 / 9$. Fig. 16 shows the model 3 of $\beta=8 / 9$. The rotor is the same as model 2 . The output power and efficiency are shown in table 2 .

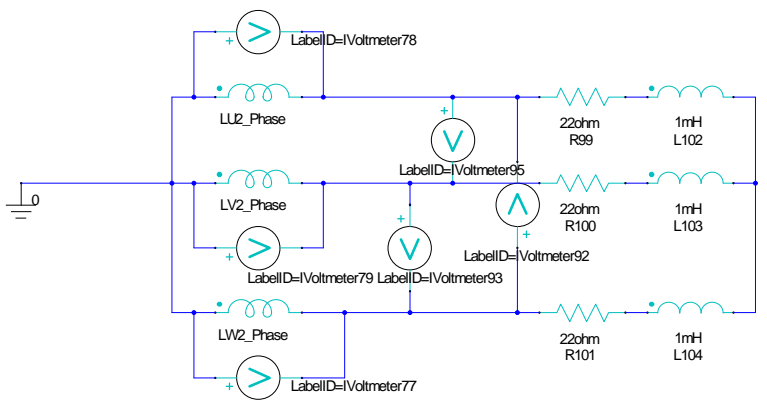

Fig. 11 External circuit.

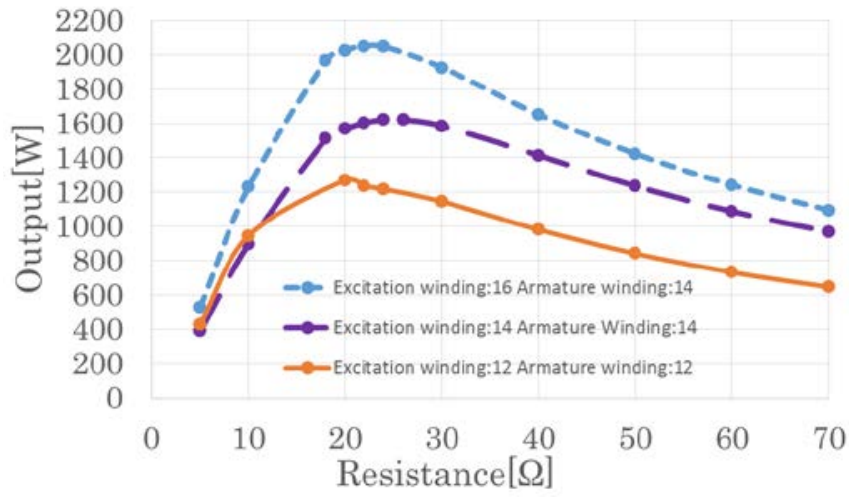

Fig. 12 Output power characteristics $(L=0.01 \mathrm{mH})$.

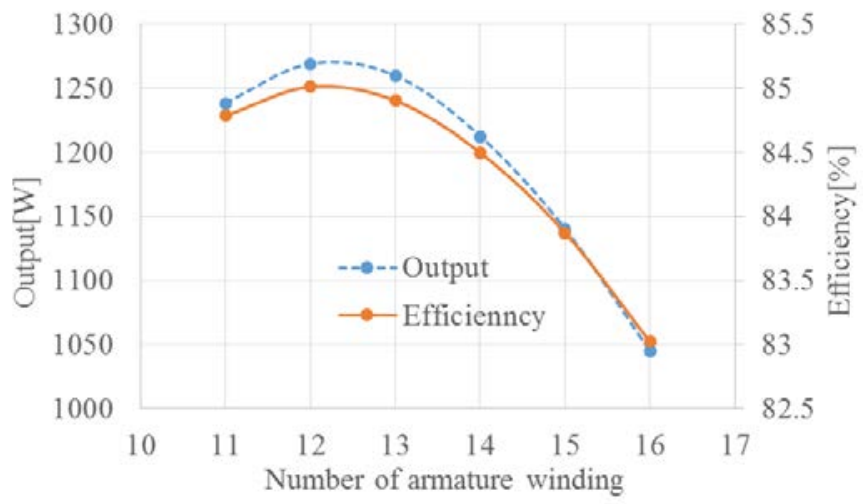

Fig. 13 Output power and efficiency characteristics. (Excitation winding: 12) 


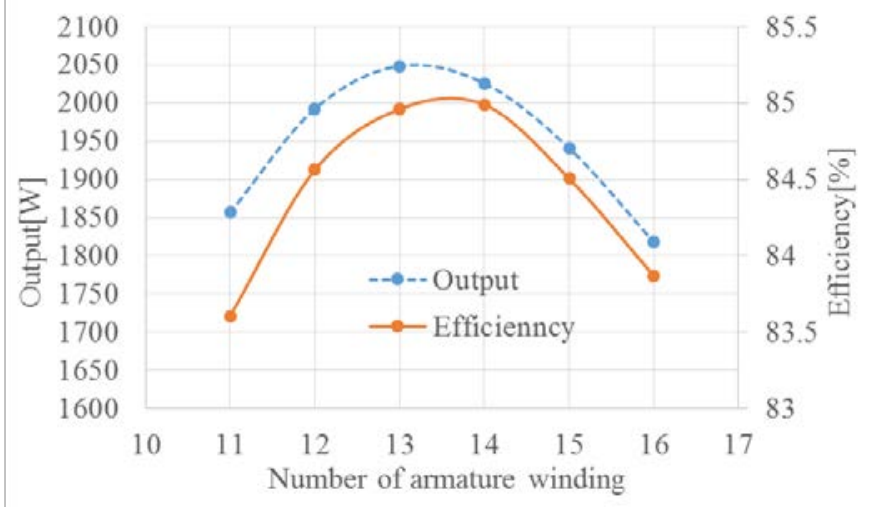

Fig. 14 Output power, efficiency characteristics.

(Excitation winding: 16)

Table. 1 Output power characteristic and space factor

\begin{tabular}{|c|c|c|c|}
\hline $\begin{array}{c}\text { Excitiation } \\
\text { winding }\end{array}$ & $\begin{array}{c}\text { Armature } \\
\text { winding }\end{array}$ & $\begin{array}{c}\text { Output } \\
\text { Power[W] }\end{array}$ & $\begin{array}{c}\text { Efficiency } \\
{[\%]}\end{array}$ \\
\hline 12 & 12 & 1268.7 & 85.0 \\
\hline 16 & 14 & 2048.2 & 85.0 \\
\hline
\end{tabular}

Both output power and efficiency of the model 2 increase compared with model 1 . Because the model 1 is designed the field magnetic the flux to be sinusoidal wave form and the fundamental component is smaller than the model 2. It is shown that output power and efficiency of model 3 are improved compared with the model 2.

Their induced electromotive force wave forms are shown in Fig. 17 and Fig. 8. It is difficult to detect the difference of the wave forms. We can confirm the harmonic content of them in Fig. 19.
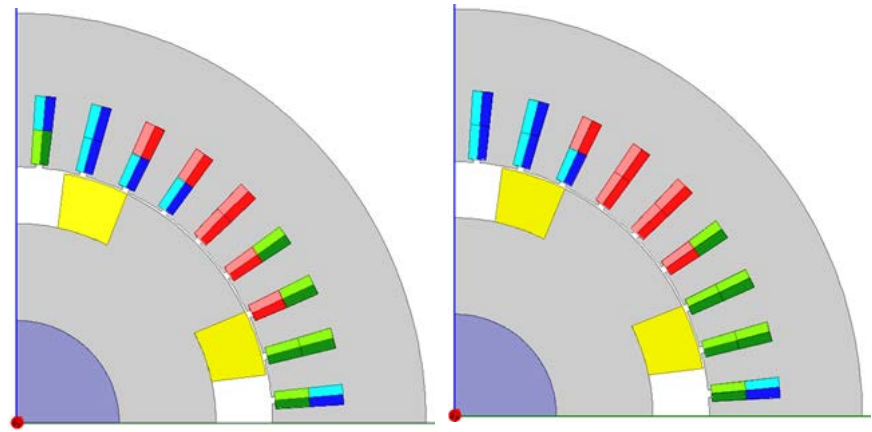

Fig. 15 Model $2(\beta=7 / 9)$

Fig. 16 Model $3(\beta=8 / 9)$

Table. 2 Output power and efficiency

\begin{tabular}{|l|c|c|}
\hline Model $(\beta)$ & Output power [W] & Efficiency [\%] \\
\hline Model 2 (7/9) & 2234.7 & 88.4 \\
\hline Model 3 (8/9) & 2487.7 & 88.7 \\
\hline
\end{tabular}

\section{Conclusions}

The half-wave rectified brushless synchronous generator was proposed and the output characteristics were analyzed.
Harmonic contents of the induced voltage were decreased by using sine wave modulation function. The output power and efficiency was improved by design of windings and rotor construction. The efficiency was $88.7 \%$ at output power of 2.5 $\mathrm{kW}$.

\section{REFERENCES}

[1] J. Oyama, S. Toba, T. Higuchi and E. Yamada, "The Characteristics of Half-Wave Rectified Brushless Synchronous Motor", in Proc. of Beijing International Conf. on Electrical Machines, pp.654-657, 1987.

[2] J. Oyama, S. Toba, T. Higuchi and E. Yamada, "The Principle and fundamental Characteristics of Half-Wave Rectified Brushless Synchronous Motor", Trans. IEE of Japan, vol.107-D, pp.12571264, 1987.

[3] J. Oyama, T. Higuchi, T. Abe and E. Yamada, "Analysis of HalfWave Rectified Brushless Synchronous Motor with Permanent Magnets", Conf. Rec. IEEE IAS Annu. Meeting, pp.781-786, 1990.

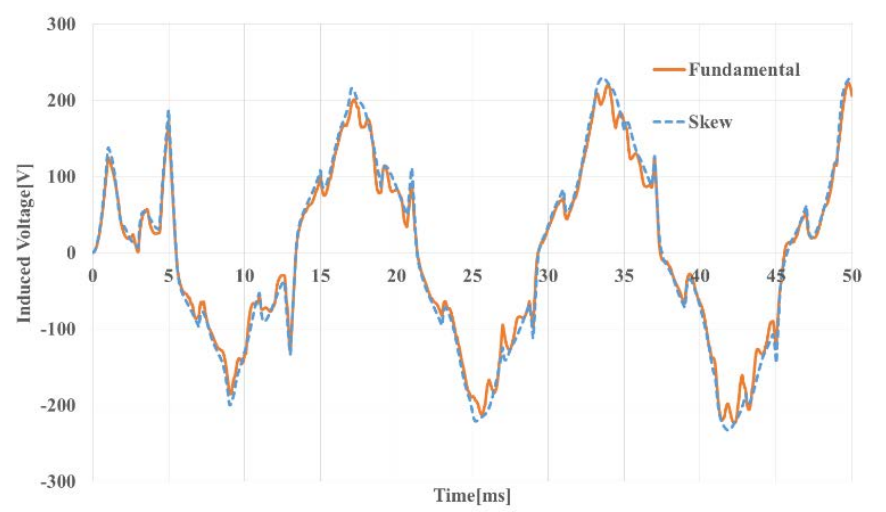

Fig. 17 Induced voltage $(\beta=7 / 9)$

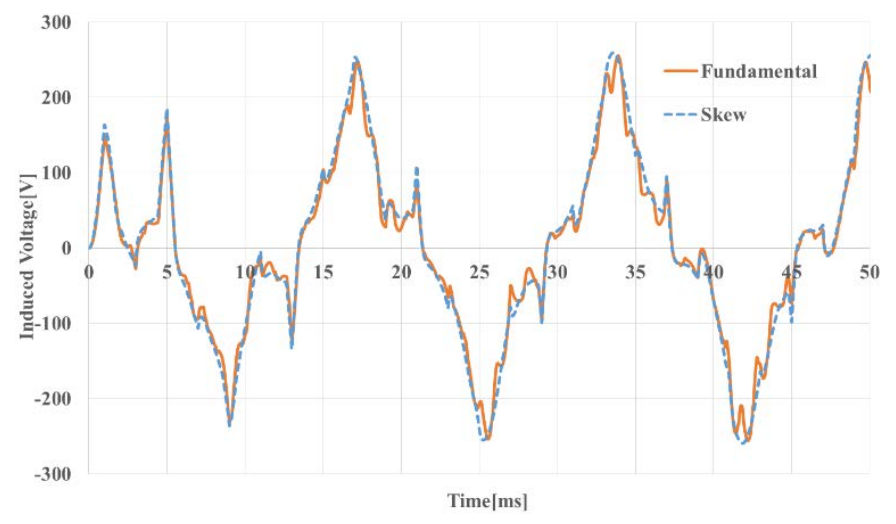

Fig. 18 Induced voltage $(\beta=8 / 9)$

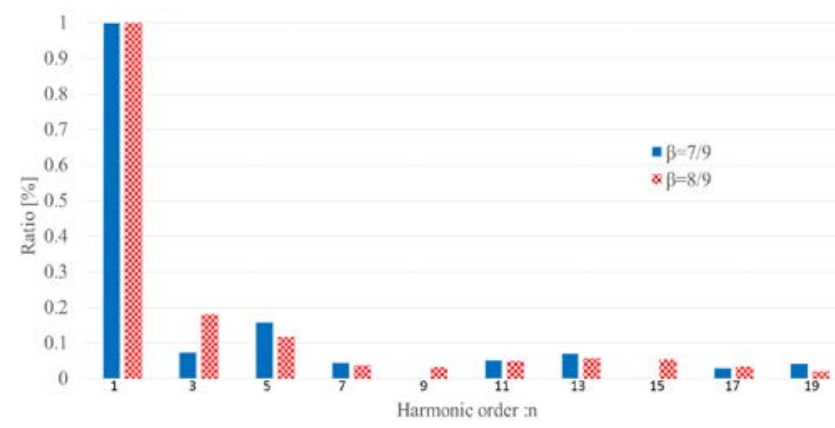

Fig. 19 Number of harmonic of induced voltage 